\title{
The Hanford Nuclear Plant: Radiation Ablation Meets History, Cultural Heritage, and Nuclear Decontamination ${ }^{\mathrm{a}}$
}

\author{
John F. Asmus ${ }^{1 \star}$, Vadim A. Parfenov ${ }^{2,3}$, Jessica P. Elford ${ }^{1}$ \\ 1 Department of Physics, University of California, San Diego, 9500 Gilman Dr., La Jolla, CA, 92093 - \\ 0360, USA \\ 2 Department of Quantum Electronics and Opto-Electronic Devices, St. Petersburg Electrotechnical \\ University; 5, Prof. Popova ul., 197376, St. Petersburg, Russian Federation \\ 3 Department of Laser Technological Systems, St. Petersburg National Research University of Infor- \\ mation Technologies, Mechanics and Optics, 49, Kronverksky pr., 197101, St. Petersburg, Russian \\ Federation \\ * Corresponding author: jfasmus@ucsd.edu
}

\begin{abstract}
The Hanford Nuclear Reservation in the state of Washington (USA) has 12 shutdown atomic reactors that were constructed about 70 years ago and established for the production of plutonium. The facility also encompasses five chemical-processing complexes for the extraction and refining of plutonium. Major activities associated with the closing of Hanford (at the end of the "Cold War") first centered on disassembling the reactors, the chemical plants, and the waste storage facilities. A remediation program was initiated to drain the leaking tanks and ponds so that the toxic wastes could be buried elsewhere and/or transferred to more secure double-shell reservoirs. This poses problems when disposing of refuse materials and hardware from the site. It has been experimentally determined that this hazardous surface contamination may be ejected by means of radiation ablation. In this procedure the dislodged surface contamination is freed to float in reactor-core water and is then captured and concentrated by the filters of the fluid circulation systems. The final phase of the project has been assistance in designing and fabricating a monumental Nuclear Reliquary to mark both the successful decontamination of the reservation and the return of the land of the Hanford site to its natural state. The artist-in-residence (James Acord) of Imperial College, London, created a small $500 \mathrm{~kg}$ trial statue (Monstrance for a Grey Horse) of the eventual kilometer-scale Hanford monument. It is currently installed in the Jimi Hendrix Seattle Rock and Roll Museum to symbolize "nuclear alchemy" in the form of an embedded capsule of benign ruthenium that had been transmuted through neutron capture from radioactive technetium $\left({ }^{99} \mathrm{Tc}\right)$. The full-scale Hanford Monument was designed prior to the death of James Acord and will again have a transmuted ruthenium core to symbolize the decommissioning of the Hanford Works. The many tons of material comprising the bulk of the Stonehenge-like structure celebrating the decontamination of the Hanford Reservation will be atomic reactor components cleaned through radiation ablation. Optical radiation ablation is favored in numerous surface-divestment applications due to inherent self-limiting and selectivity features. However, in nuclear decontamination the most profound advantage may be in cost reduction through secondary waste reduction. No abrasives (e.g.
\end{abstract}

${ }^{a}$ Presented at LACONA IX conference, The British Museum and University College London, 7-10 September 2011. 
sandblasting) or significant volumes of liquids (e.g. hydro blasting) are used. Furthermore, at high optical irradiation fluxes most toxic organic waste chemicals are destroyed and converted into innocuous gases (e.g. water vapor and carbon dioxide), and no additional secondary waste is formed. Submerged flashlamp irradiation was found to be the most economical approach for the radiation ablation.

Keywords: Decontamination, ablation, laser cleaning, flashlamp, nuclear waste, Hanford, nuclear reactor

\section{Hazardous radioactive contamination at Hanford}

The USA's nuclear weapons program known as the "Manhattan District" was established shortly after Prof. Albert Einstein wrote to President Franklin Roosevelt regarding the technical feasibility of an atomic bomb. The Los Alamos Scientific Laboratory (LASL, then LANL) was established to design and fabricate nuclear weapons. The Oak Ridge facility was established in order to refine uranium in order to concentrate ${ }^{235} \mathrm{U}$ for uranium gun-design devices such as Little Boy. The Hanford Works facility was established in eastern Washington State in order to produce plutonium $\left({ }^{239} \mathrm{Pu}\right)$ for the Fat Man Implosion weapon.

When the Hanford nuclear reactor facility was established and expanded throughout the 1940s and 1950s, long-term storage and disposal of radioactive waste was not recognized as a significant problem. With the enactment of the SALT treaties and by the end of Cold War tensions, it was recognized that the Hanford Reservation was no longer needed. When plans for its closing were drawn up and assessed, it was established that very serious nuclear waste decontamination and disposal issues had to be confronted [1].

Major activities associated with the closing of Hanford first centered on disassembling the reactors, the chemical plants, and the waste storage facilities. Radioactive parts and assemblies were to be transported across state boundaries to the Yucca Mountain long-term underground storage caverns in the western wilderness of the state of Nevada. However, a number of developments conspired to obstruct this plan. First, there was a political impasse. The citizens of the State of Nevada objected to the importation of dangerous toxic substances into their state. Second, there was a related financial problem associated with the preparation and transportation of a prodigious mass of contaminated materials. Finally, it was discovered that significant quantities of radioactive wastes were leaking from storage containment vessels and ponds into the soils and aquifers beneath Hanford (Fig. 1). It was discovered that the liquid wastes were seeping toward the Columbia River. Upon reaching the river, the contamination would next be swept onto the extremely important Kennewick archaeological dig, which may hold secrets of the human migration to North America. Major population centers such as Portland and Vancouver are further downstream, and together with Kennewick may have to be evacuated as in the cases of Chernobyl and Fukushima. Consequently, funds that were destined to close Hanford and move the nuclear wastes to Nevada had to be redirected toward the prevention of the radioactive polluting of a major river. This entails moving the wastes to more secure newer double shell reservoirs, decontaminating the old containment facilities, and stopping the underground seepage toward the river. 


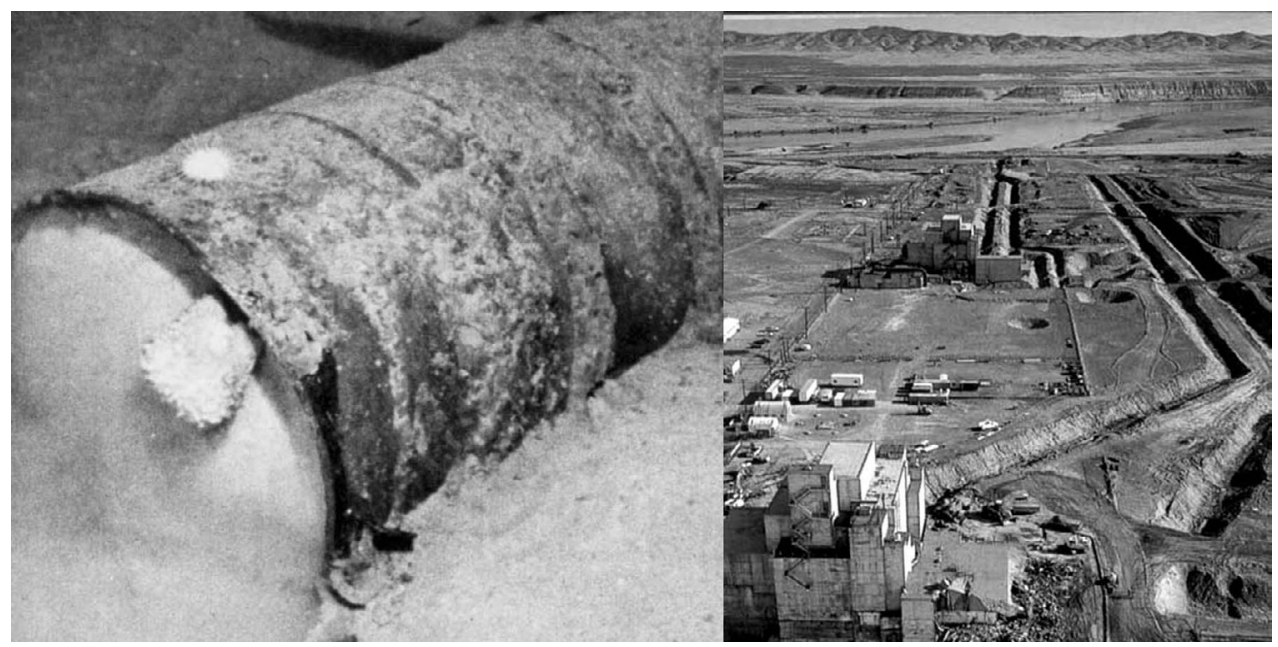

Fig. 1. A corroded and leaking nuclear waste storage drum (left). Hanford nuclear reactor and its earthen waste drainage ditches with leaking liners (right).

In anticipation of the eventual complete decontamination of the entire nuclear facility and the removal of radio-active isotopic waste materials to secure storage sites it was expected that the Hanford Reservation would be rededicated as an environmental-cleanup-demonstration National Park. The park's centerpiece would be a monument designed by Hanford's "nuclear artist-in-residence," Mr James Acord (Imperial College, London.) The monument is to be fabricated from reactor components that have been decontaminated either by conventional or radiation-ablation (flashlamp) procedures. In preparing for the full-scale monument, Acord created a small $500 \mathrm{~kg}$ trial statue (Monstrance for a Grey Horse) of the eventual kilometer-scale Hanford monument. This anticipatory piece is currently installed in Paul Allen's “Jimi Hendrix Seattle Rock and Roll Museum" in order to symbolize "nuclear-alchemy" decontamination, in the form of an embedded capsule of benign ruthenium that was transmuted through neutron capture from radioactive technetium $\left({ }^{99} \mathrm{Tc}\right)$.

\section{Nuclear reactor accidents}

Human errors, natural events, and engineering deficiencies have also led to the spread of hazardous radioactive contamination. A portion of the Hanford problem has been traced to the accidental opening of a valve that drained radioactive and toxic chemicals directly into the aquifer. This tragedy was exacerbated by the tardy realization of the human mistake. Apparently, the Chernobyl disaster is traced to a similar human error. The Fukushima explosion and partial meltdown can be attributed to the natural catastrophe (earthquake and associated tsunami) and/or to an inadequate engineering safety margin and emergency safety plan.

Chernobyl released from $1 / 100$ to $1 / 1000$ of the total amount of radioactivity released by nuclear weapons testing during the 1950s and 1960s. Approximately $100,000 \mathrm{~km}^{2}$ of land was significantly contaminated with fallout, with the worst hit regions being in Belarus, Ukraine and Russia. Four square kilometers of pine forest directly downwind 
of the reactor turned reddish-brown and died. In addition, the radioactive contamination of aquatic systems is also a problem in the aftermath of the accident. However, the greatest problem of the Chernobyl incident pertains to health as it may have resulted in $10,000-200,000$ additional human deaths in the period between 1990 and 2001. Therefore, the Chernobyl accident made it quite clear (perhaps, for the first time in human history) that the contaminants released after a severe nuclear accident may spread over large areas, and thereby come to form a significant external radiation hazard not only on-site in the place of a disaster, but also in surrounding areas of high population density. In any event, all require major decontamination efforts for the safety of the human populations as well as to return the local environments to habitability and productivity. We anticipate that the radiation-ablation decontamination procedure developed at Hanford may be useful under such circumstances.

\section{Kennewick Man downstream from the Hanford spill}

In 1966 the skeletal remains of a 9,300-yearold Caucasian male were discovered on the shore of the Columbia River near the town of Kennewick, Washington. The skull (and bones at a later time) was found by two college students while watching hydroplane races. The office of the Benton County Coroner determined that the skeleton was not the result of a contemporary homicide, but was the consequence of the natural death of an "Ancient One" at least 9,200 years earlier. The remains of this five-foot ten-inch male (1.8 meters) were determined to be $90 \%$ complete and are among the oldest ever found in North America. Furthermore, a two-inch $(5 \mathrm{~cm})$
"Clovis" spear point was found imbedded in his pelvis. The bone exhibited signs of healing indicating that he had survived a hostile attack.

Predictably, the discovery of Caucasian remains that predated the earliest Asian remains found in North America turned asunder the generally accepted theory of the human migration across the Siberian-Alaskan land bridge at the end of the last Ice Age. The discovery of the Caucasian Kennewick Man seemingly lent support to theories postulating that seafarers who originated in or near Europe initially populated North America. Nevertheless, Native American Indian tribes (of Asian origin) claimed Kennewick Man as an ancestor and requested custody of the remains in order to perform a traditional religious burial. This issue became the subject of a court battle between anthropologists who wished to learn all they could about the relic and the U.S. Army Corps of Engineers (owner of the Columbia River shoreline at Kennewick) wanting to have it reburied in accordance with tribal wishes in order to put an end to the controversy. The local tribes (Umatilla, Nez Perce, Yakima, Wannapum, Warm Springs Nation, and the Colville Nation) maintained that the skeleton should be reburied without further study. They had no explanation as to how their "ancestor" could be Caucasian.

At the heart of this controversy is the rewriting of American pre-Columbian history. Consequently, a group of anthropologists joined in the lawsuit in 1996. This caused five of the Indian tribes to fight the anthropologists in court contending that the repatriation law covered Kennewick Man, and that scientific examinations disrespected Native American beliefs about the sanctity of their dead. In 2002 Judge Jelderks ruled in favor of the anthropologists. The U.S. Ninth 
Circuit of Appeals upheld that ruling in 2004. Subsequently, the relics have been placed in temporary storage in the basement of the Burke Museum. Twenty-two anthropologists have studied the skeleton and have performed thousands of measurements by means of radiocarbon dating, MRI, and DNA analysis. It was determined that he died in his 30 s, but not from the spear wound. In light of the ongoing litigation and the possibility that the remains of the Kennewick skeleton will eventually be reburied (especially because the bones have already been studied so extensively) it is imperative to decontaminate Hanford before radioactivity reaches the burial site and other relics yet to be found.

\section{Flashlamp ablation of nuclear contamination}

The disassembly, cleanup, decontamination, and decommissioning of the Hanford facility is an enormous task in its entirety. Soils and groundwater are polluted with radioactive isotopes and toxic chemicals, as are chemical processing plants, chemical handling equipment, and storage areas. Contaminated nuclear reactors together with spent fuel, fuel cores, and water-cooling and moderating systems present a wide range of technical and logistical cleanup issues. If large, heavy, and bulky equipment can be economically cleaned, only the concentrated hazardous waste substances will require expensive transportation to, and long-term storage in, secure facilities such as Yucca Mountain. There are several advantages of light ablation surface treatments over conventional stripping and cleaning techniques. Some of these are inherent in the technology and benefit any suitable application. Other advantages are specific to the area of radioactive contamination removal and relate to special problems faced at the Hanford site [as well as other U.S. Department of Energy (DOE) and commercial nuclear facilities]. Optical radiation ablation is favored in numerous surface-divestment applications due to inherent self-limiting and selectivity features. However, in nuclear decontamination the most profound advantage may be in cost reduction through secondary waste reduction. No abrasives or significant volumes of liquids are used. Moreover, at high optical irradiation fluxes most toxic organic waste chemicals are destroyed and converted into innocuous gases, and no additional secondary waste is formed. Fig. 2 (left) shows, as an example, the flashlamp removal of contaminated rust from a steel beam. Figure 2 (right) is a pho-
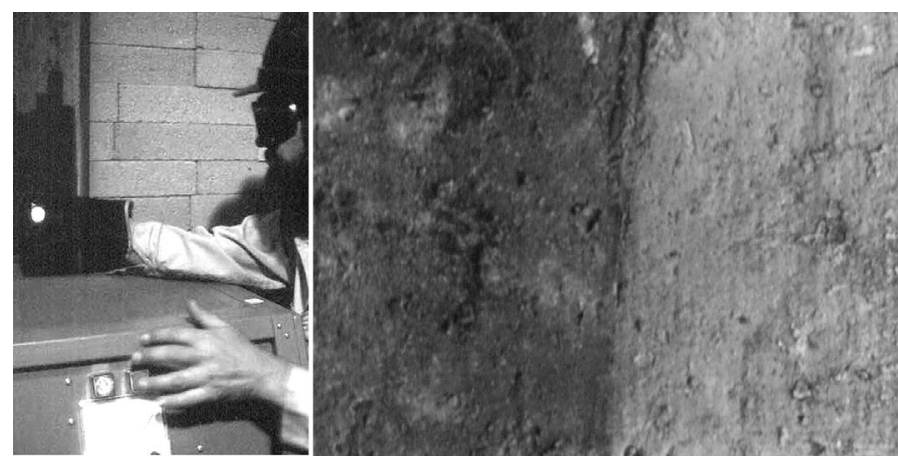

Fig. 2. Xenon flashlamp surface ablation in air of contamination on a steel beam (left). Concrete surface contamination on left and flashlamp divested region on the right side. (right) 
tograph revealing flashlamp divestment of a contaminated crust from concrete through radiation spallation (under water). Figure 3 presents measurements of the rates at which

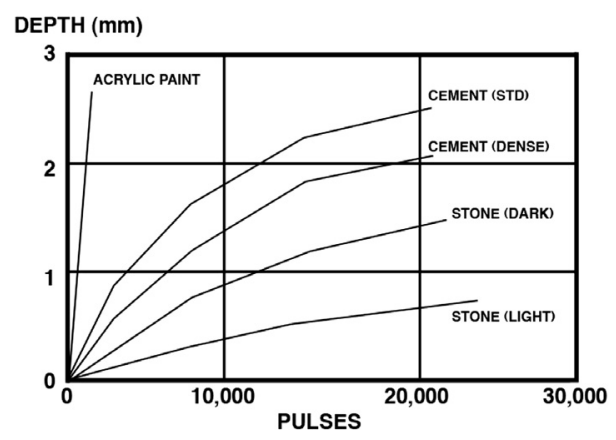

Fig. 3. Experimental flashlamp ablation rates for the materials of nuclear reactor fuel water pools at an incident underwater optical flux of $8 \mathrm{~J} / \mathrm{cm}^{2}$.

high-power flashlamp radiation ablates the contaminated surfaces of materials encountered at water-moderated reactor vessel walls. Flashlamp, rather than laser, radiation was employed in these investigations due to the enormous areas to be processed and the over-riding importance of cost effectiveness.

The following specific problem areas at Hanford have been identified for possible application of flashlamp ablative decontamination [2].

1. Cell wall decontamination.

2. Waste Encapsulation Storage Facility (WESF) cell decontamination prior to transuranic (TRU) monitor test installation. The purpose would be to reduce gamma background to prevent interference with neutron detection instrument testing and operation.

3. Cell decontamination.

4. The Reduction Oxidation (REDOX) Plant is scheduled to be the first canyon building onsite to undergo complete decon- tamination and decommissioning. The $\mathrm{B}$ Plant may also require limited cell decontamination in the next few years to accommodate WESF support operations.

5. The areas to be decontaminated include the tank exterior surfaces and cell walls. This will involve both paint stripping and concrete spalling.

6. Double shell tank-waste retrieval pumps and equipment. After water or chemical flushing the interiors of the pipe and pumps, and the exterior may be irradiated to further reduce contamination and corrosion.

7. Hot-cell and glove box laboratory instruments.

8. Lead brick shielding used in laboratories, hoods, canyons, and cells that have developed corrosion films that have collected radioactive surface contaminants, (characterized as mixed wastes).

9. Fast Flux Test Facility (FFTF) equipment maintenance and field operations.

10. Single-shell tank clean-out equipment.

11. Core sampling equipment. Maintenance tools. Organic destruction.

12. Destruction of complex concentrated organics from the thin-film reactor process. Repair of hot-cell electrical equipment that is intolerant to water/acid/salt decontamination.

13. Fuel/Capsule storage pools.

As most of the decontamination operations listed above are favorably performed under water (in order to contain the ejected contaminants), submerged flashlamp irradiation experiments were performed. Figure 4 (employing laser, rather than flashlamp ablation for photographic clarity) reveals how optical irradiation under water constrains the blow off plasma, thereby increasing the surface impulse. 


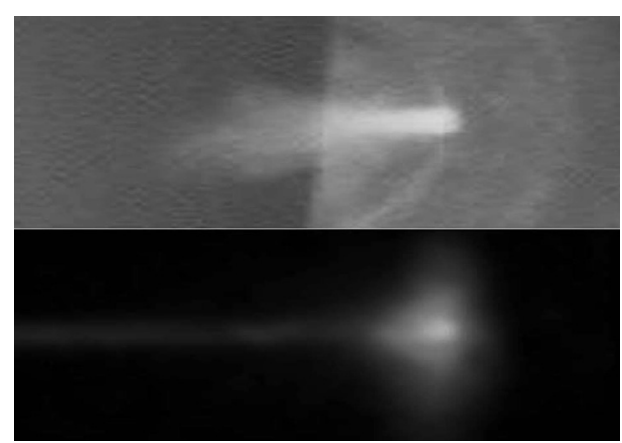

Fig. 4. Blow-off plasma luminosity from laser irradiation $\left(1.06 \mu \mathrm{m}, 250 \mu \mathrm{s}, 8 \mathrm{~J} / \mathrm{cm}^{2}\right)$ of concrete in air (top) and underwater (bottom).

Figure 5 demonstrates that performing the optical ablation underwater enhances the strength of the impulse over that generated in air. Furthermore, underwater ablation facilitates capturing the contamination in the water

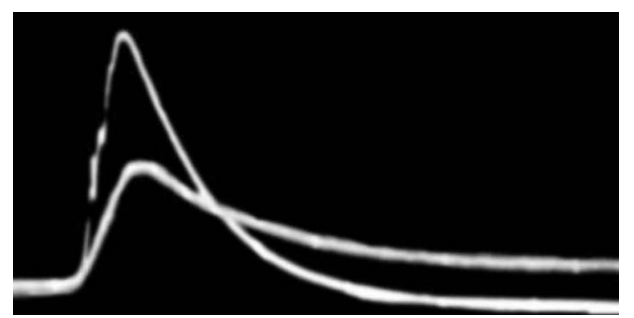

Fig. 5. Impulse from laser irradiation of a surface in air (lower trace) and underwater (upper trace)

so that filtration systems readily collect and concentrate the radioactive waste. Observing the system in operation above a reactor pool is seen in Fig. 6. The technologies (including flash ablation) to clean up the various contamination zones at Hanford have been developed and tested. Unfortunately, radioactive seepage and migration continues as the political roadblock to the use of Yucca Mountain for long-term storage remains unresolved. However, as the radioactive contamination threat to high population areas grows, a political accommodation must be reached.

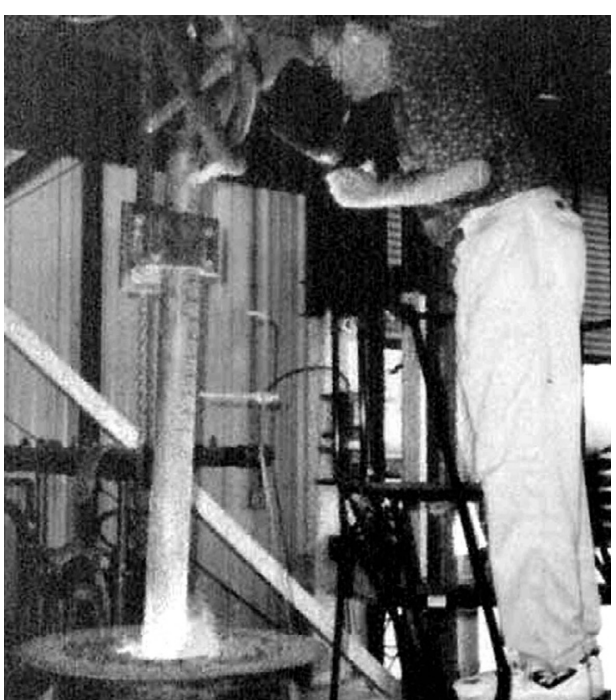

Fig. 6. Observing the flashlamp ablation process taking place within a nuclear reactor fuel core water pool.

\section{New trends in laser ablation technologies for nuclear decontamination}

In the case of decontamination at the Hanford nuclear facilities flashlamp ablation was more effective than laser processes. However, sometimes, the potential of laser cleaning may be very useful. Laser cleaning is an effective method of removal of soiling particles of different materials and sizes, as well as films and coatings from a solid surface [3]. This is a nontoxic and inexpensive technology and can be used for removal of various contaminants, including those that cannot be removed by the conventional techniques. As laser cleaning employs low levels of radiation intensity, contamination removal can be realized not only by means of evaporation, but also in the solid phase. In this case thermal influence on the substrate is very small. Variations in laser output parameters on a large scale allow one to choose the generation regime specifically for removal 
of every type of surface contamination. Laser cleaning also has other advantages, such as operation at a distance, absence of mechanical damage of the surface, and cost effectiveness.

For the removal of nuclear contamination one can use direct laser ablation. Such an approach has been realized in the framework of the project to decontaminate the Hanford nuclear reactors. Regarding new trends in the development of laser cleaning techniques for nuclear decontamination, we point out an attractive approach to the problem of removal of nuclear contaminants which has been proposed by a group of scientists with the National Research University of Information Technologies, Mechanics \& Optics (St. Petersburg, Russia). They have further developed a technology which is called LIFT (laser-induced films transfer). The main idea of this approach is surface cleaning through a transparent film. This film is a collector which inhibits soiling of the surface [4].

In a number of cases of laser cleaning the necessity of avoiding re-soiling of the surface arises. The most striking example of such a task is the decontamination of components and details of nuclear power installations. It is known that applying nanosecond pulses of laser radiation (for instance, Nd:YAG laser) allows one to remove surface corroded layers up to $200 \mathrm{~nm}$ thickness without melting or evaporation of the substrate. The experts of the above-mentioned Russian university developed the method of nuclear decontamination, by which the laser beam affects the surface through the thin film, which is transparent at a wavelength of $1.06 \mu \mathrm{m}$.

The main advantage of this technique is that the film separates the "dirty" machining zone from the "clean" and also adsorbs the products of cleaning on to the glue film surface that faces the treated object. This facilitates the collection and concentration of the radioactive waste.

\section{Conclusions}

The story of discovery of Kennewick Man stresses the very real problem of nuclear decontamination in the USA, which is a part of a global problem of our civilization. The solution to this problem may be realized through the use of radiation ablation technologies (based either on laser or flash-lamp cleaning).

Within the programs of decommissioning of the Hanford facility it was found that the hazardous surface contamination may be removed by light ablation: literally blowing it off as a cloud of plasma, using photons. It was shown that this is cost-effectively accomplished through surface decontamination by irradiation with an underwater xenon flashlamp. In this case the dislodged surface contamination floats in the water and can then be captured and concentrated by the filters of the fluid circulation systems for safe disposal elsewhere. There are several advantages of light ablation surface treatments over conventional stripping and cleaning techniques, one of which is that it generates no secondary waste to be disposed of. Therefore, further development of light ablation technologies is a task requiring systematic practical field investigation.

As for radioactive seepage from Hanford, it will reach the Kennewick region in a few decades if the present advance rate continues. At that point millions of inhabitants in Portland, Vancouver, and smaller cities will face evacuation as in the case of the Chernobyl and Fukushima disasters. This prospect may break the political impasse and a site will be selected to receive the Hanford waste and the 
radiation ablation decontamination of the facility will proceed in haste. The excavation of the area around the Kennewick Man discovery will proceed and the anthropological mystery of the populating of the Americas may be resolved through acceleration of the ongoing investigations. In conclusion we should mention that sometimes absolutely diverse disciplines unpredictably intersect. In this case study of the Kennewick Man, radiation ablation met history and cultural heritage, and it is really a very surprising mismatch. However, in the past two decades laser cleaning technology was very frequently used in artworks conservation, making the application of laser techniques in cultural heritage preservation [5] an entirely routine approach. However, the discovery of the Kennewick Man (and the creation of the James Acord decontamination monument) is exceptional, because here issues connected with use of lasers in nuclear decontamination were surprisingly "mixed" with cultural heritage and anthropology.

\section{References}

[1] U.S. Department of Energy, Disposal of U.S. Department of Energy, Disposal of Hanford defense high-level transuranic and tank wastes, Public Document, DOE/EIS-0113, vol. 5 (December 1987), available from https://energy.gov/nepa/downloads/ eis-0113-final-environmental-impact-statement-0 (accessed 8.07.2017).

[2] Westinghouse Hanford Company, Light Aided (Laser) Decontamination, Westinghouse Document, WHC-SD-WM-TI-518 (1992).

[3] B. S. Luk'yanchuk (Ed.), Laser cleaning, B.S. Luk'yanchu World Scientific, Singapore 2002.

[4] V.P. Veiko, T.Y. Mutin, V.N. Smirnov, E.A. Shakhno, "Laser decontamination of radioactive nuclides polluted surface”, Laser Physics, 21 (2011) 608-613, DOI: 10.1134/S1054660X11050264.

[5] C. Fotakis, D. Anglos, V.Zafiropulos et al., Lasers in the Preservation of Cultural Heritage. Principles and Applications, CRC Press, Taylor \& Francis Group, Boca Raton, USA 2007. 
